RESEARCH REPORT

\title{
Crohn's disease, ulcerative colitis, and measles vaccine in an English population, 1979-1998
}

\author{
V Seagroatt, M J Goldacre
}

J Epidemiol Community Health 2003;57:883-887

See end of article for authors' affiliations

.....................

Correspondence to: Ms V Seagroatt, Unit of Health-Care

Epidemiology, Department of Public Health, University of Oxford, Old Road, Oxford OX3 7LF, UK; valerie.seagroatt@ dphpc.ox.ac.uk

Accepted for publication 8 April 2003

\begin{abstract}
Study objectives: To study the hospitalised incidence of Crohn's disease (CD) and ulcerative colitis (UC) from 1979 to 1998; and to determine whether the introduction of the measles vaccination programme was associated with an increase in the young.

Design: Analysis of linked data on hospital admissions; a cohort analysis of the effect of the measles vaccination programme on the incidence of hospitalised $C D$ and UC; and a comparison of these results with those from previous studies on the association between measles vaccine and CD or UC.

Settings: Southern England.

Subjects: People admitted to hospital with a main diagnosis of CD (1959 people) or UC (2018 people). Main results: Overall, the incidence of hospitalised CD showed no significant change over the 20 year period: the average change per year was $0.08 \%$ ( $95 \%$ confidence interval: $-0.7 \%$ to $0.9 \%)$. The relative risk associated with the measles vaccination programme was not significant (0.91: 0.5 to 1.4). The estimate differed significantly from the relative risk of 3.0 obtained in the original study reporting an association, but agreed with the combined estimate from three subsequent studies (0.95: 0.6 to 1.5). The results for UC were similar.

Conclusions: The incidence of hospitalised CD and UC remained stable over the 20 years, 1979 to 1998. Whatever caused the marked increases in CD and UC in the mid-20th century must itself have stabilised in this region. These results, together with those from other studies, provide strong evidence against measles vaccine causing $C D$ or $U C$.
\end{abstract}

C rohn's disease (CD) and ulcerative colitis (UC) are chronic inflammatory diseases of the gastrointestinal both inct. Their aetiology is unknown but the incidence of during the early and middle part of the 20th century. ${ }^{1}$ From the 1980s their incidence has probably levelled off in most but perhaps not all such countries. ${ }^{1}$

We have used data from linked hospital statistics in a region of England to study changes in the incidence of the inflammatory bowel diseases (IBD), CD and UC, from 1979 to 1998. We were particularly interested to know whether trends in young people were similar to those in older people; and whether any changes in incidence were related to the introduction of the measles vaccination programme. A marked, positive association between measles vaccine and IBD was found in the first study published on this topic, ${ }^{2}$ but not confirmed in others. ${ }^{3-5}$ We hypothesised that, if measles vaccine is a cause of IBD, its introduction in 1968 would have resulted in a marked increase in IBD in those cohorts offered the vaccine as infants. We examined this possibility by comparing the estimates of incidence of CD and UC across birth cohorts.

\section{METHODS}

\section{Estimates of incidence}

We used statistical data from the Oxford Record Linkage Study ${ }^{6}$ on hospital admissions in five of the six health districts that were covered by the data collection from 1974 to 1998 (population: 1.4 million). We excluded data for one district because some of its residents had been included in an earlier Medical Research Council trial of vaccine efficacy, and their inclusion would have complicated our cohort analysis. We confined the analysis to people resident in the five districts and excluded day cases. We selected admissions with a main diagnosis of $\mathrm{CD}$ (International Classification of
Diseases (ICD) codes, 7th revision, 572.0; ICD-8, 563.0; ICD-9, 555; and ICD-10, K50) or UC (ICD-7: 572.2, ICD-8: 563.1, ICD-9: 556, ICD-10: K51).

We wanted to study changes in incidence but the date of first-ever diagnosis is not recorded in routine hospital statistics. To minimise lead-time bias in the ascertainment of cases, we restricted our analyses to patients without a prior admission for CD or UC within five years. We took this ratestrictly speaking, five year period prevalence-as a proxy for incidence. As data on admissions in the five districts were available from 1974 onwards, we were able to estimate admission rates, defined in this way, from 1979.

\section{Statistical analysis}

Analysis of trends

We used Poisson regression to estimate trends in rates and their statistical significance. Log-linear models with a linear term for year of admission were fitted to the observed counts of patients with CD or UC in each calendar year, with adjustments for sex and age. Age was analysed in five year groups: less than 5 years, 5-9, 10-14, etc. The models were fitted using GLIM. ${ }^{7}$ The fitted parameter for trend (linear on a log scale) was expressed as the percentage change in rates per year. To determine whether trend varied by age, the data were grouped into six broad bands: less than $15,15-24,25-34,35-44,45-54$, and 55 years and over. A model was fitted with separate linear trends for each age group. If this produced a significant improvement in fit, compared with fitting the model with a common trend, then the trend was judged to vary with age. Differences between

Abbreviations: $C D$, Crohn's disease; UC, ulcerative colitis; IBD, inflammatory bowel disease 


\section{Key points}

- There was no increase in Crohn's disease or ulcerative colitis during the 20 year period 1979 to 1998 . This contrasts with marked increases found during earlier decades of the 20th century in westernised populations.

- Whatever factor or factors caused the earlier increases must now be stable in this region.

- Rates of Crohn's disease and ulcerative colitis were no higher in cohorts born after the introduction of the measles vaccination programme than in the earlier cohorts.

- The results from our ecological analysis together with those from three-person based studies refute the hypothesis that measles vaccine is associated with any marked increase in Crohn's disease or ulcerative colitis.

the trends for males and females were assessed in a similar way.

Association between measles vaccine and IBD

We calculated age specific rates for hospitalised incidence for five-year birth cohorts. The cohort of people born in 19621966 was the last five-year cohort not included in the measles vaccination programme; and the cohort of 1967-1971 was the first in the programme. If measles vaccine increased the subsequent risk of $\mathrm{CD}$, then the incidence of $\mathrm{CD}$ in the latter cohort would be higher than in the former cohort. The ratio of incidence rates of CD in the 1967-1971 birth cohort relative to those for the 1962-1966 cohort was estimated by using log-linear models that adjusted for age and sex. The analysis was restricted to these two five-year cohorts to minimise possible effects of period and changing vaccine uptake.

\section{Policy implication}

- This study provides further reassurance about the safety of the measles vaccination programme in respect of Crohn's disease and ulcerative colitis.

The rate ratios were converted to relative risks (RRs) for the association between measles vaccine and CD as follows. We reasoned that the observed incidence in the 1967-1971 birth cohort would depend on both the percentage vaccinated in the cohort and the actual RR for the association. (For instance, if the true RR were 3 and the vaccine uptake were $50 \%$, then the observed rate ratio would be 2 , all else being equal.) The vaccine uptakes for the years 1968 to 1971 were $33 \%, 45 \%, 51 \%$, and $53 \%$ for those born in England and Wales. ${ }^{8}$ The data on uptake for 1967 were not available, but it was likely to be lower than $33 \%$. We took the median of these values, $45 \%$, as approximating the percentage for the five year birth cohort, 1967-1971. Data on vaccine uptake for the Oxford region were only available from $1974 .{ }^{8}$ As the uptake was a little higher than the national average, ${ }^{8}$ the analysis of relative risks was repeated taking a higher estimate of $55 \%$.

The RR for UC was calculated in a similar way.

\section{Comparison of estimates of association between measles vaccine and IBD}

We considered the study that originally linked measles vaccine to $C D$ and $U C$ as a hypothesis generating study, and the others as hypothesis testing studies. RRs from the hypothesis testing studies were combined by taking their weighted geometric means, using as weights the reciprocals of the variances of the logarithms of the RRs or odds ratios. (Given that CD and UC are rare diseases, the odds ratios from the case-control studies would approximate to RRs.) The combined estimates were then compared with those from the original study by a $\chi^{2}$ test for heterogeneity.

\begin{tabular}{lllll}
\hline $\begin{array}{l}\text { Table } 1 \\
100\end{array} 000$ Number of cases of Crohn's disease and ulcerative colitis, incidence rates per \\
pond average annual percentage changes in incidence rates with \\
their $95 \%$ confidence intervals, overall and by age group and sex, for period 1979-1998
\end{tabular}



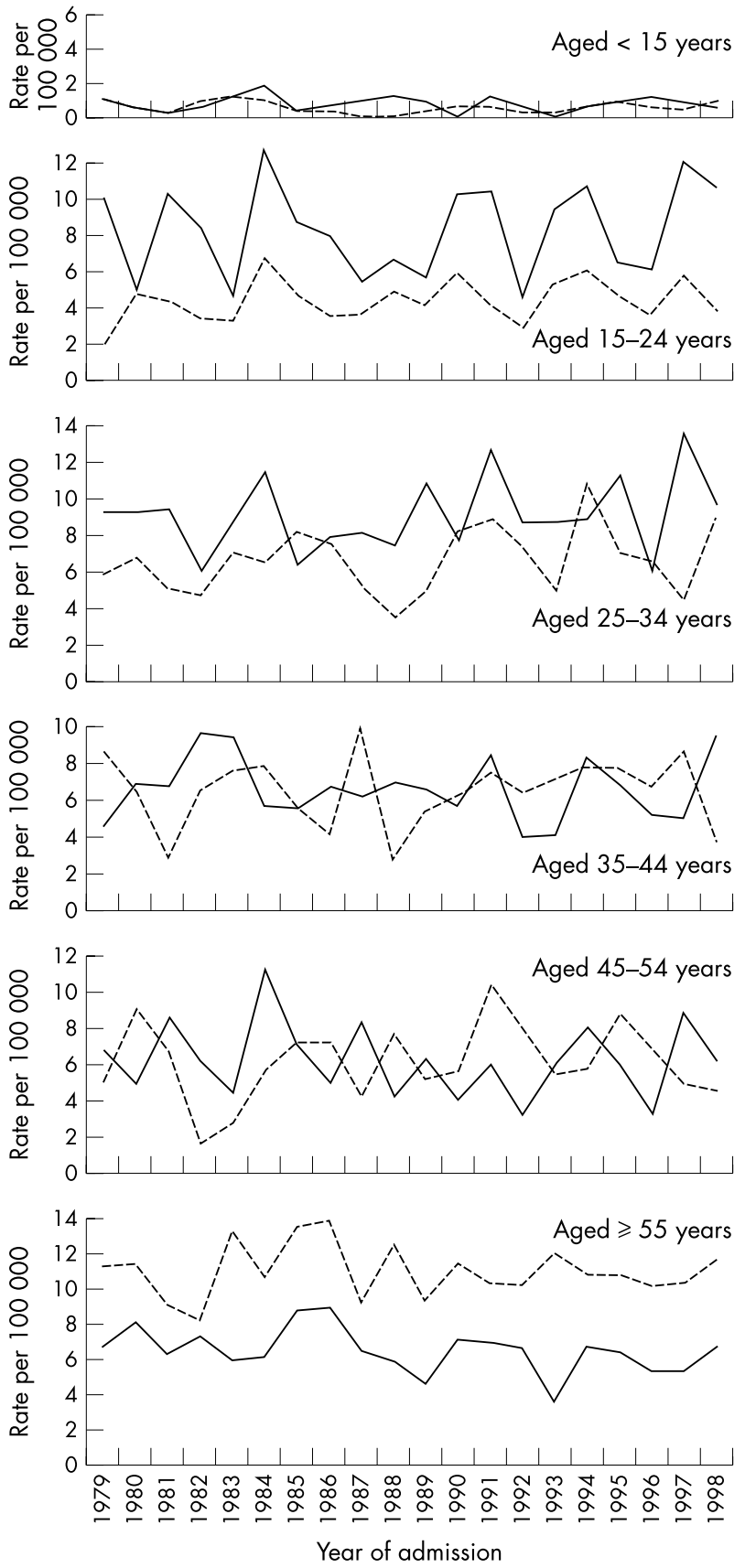

Figure 1 Trends in estimated incidence of Crohn's disease and ulcerative colitis in the Oxford region from 1979-98 for broad age bands. The solid lines denote the CD trends and the dashed lines the UC trends.

\section{RESULTS}

The criteria for inclusion were met by 1959 individuals with CD and 2018 individuals with UC.

\section{Trends in incidence}

Overall, the incidence of CD changed by, on average, $0.08 \%$ per year and that for UC, by $0.10 \%$ per year (table 1 ). These were not significant $\left(\chi^{2}=0.04\right.$ and 0.07 respectively, $\mathrm{df}=1$, $p \geqslant 0.9$ ). There were no obvious trends for any of the individual age groups for $\mathrm{CD}$ and $\mathrm{UC}$ (fig 1 ). The rates fluctuated somewhat but this variation was to be expected given the comparatively small numbers on which they were based. Expressing these trends as percentage changes per year, there were only minor and non-significant differences between the age groups for CD and UC-the youngest and oldest showed a slight decrease and the remainder a slight increase (table 1). There were also no significant differences between the trends for males and females.

\section{Association between measles vaccine and IBD}

The results from the log-linear models showed no significant increase associated with the introduction of measles vaccine: the age adjusted ratios for the incidence in the post-measles and pre-measles vaccine cohorts were 0.96 for $C D$ and 1.04 for UC (table 2). Using the estimate of uptake derived from the national data (45\% for the 1967-1971 cohort), the RRs were 0.91 (95\% confidence intervals: 0.5 to 1.4) and 1.09 (0.5 to 1.8 ) for $\mathrm{CD}$ and UC respectively (table 3 ). Repeating the analysis, taking the vaccine uptake to be $55 \%$ (to allow for higher uptakes in the Oxford region), the RRs were similar at, respectively, 0.93 (0.6 to 1.3 ) and 1.07 (0.6 to 1.6 ).

\section{Comparison of results with those from other studies}

The original study by Thompson $e a^{2}$ reported RRs of 3.0 and 2.5 for CD and UC respectively. Our estimates were lower than these values, significantly so for $\mathrm{CD}\left(\chi^{2}=7.0\right.$ : $\mathrm{df}=1$; $p=0.008)$ but not for UC $\left(\chi^{2}=2.7: p=0.099\right)$. Three studies published after the original paper ${ }^{2}$-one cohort study ${ }^{4}$ and two case-control studies ${ }^{3}$-found no evidence of any association either individually or when their results were combined (table 3). The combined RRs of 0.92 for CD and 0.96 for UC were consistent with our estimates.

\section{DISCUSSION}

\section{Trends in incidence}

Our data from the Oxford region of England showed only minor and non-significant changes in the incidence of $C D$ and UC over the 20 year period 1979-1998: the rates for CD and UC increased by, on average, $0.08 \%$ and $0.10 \%$ per year. We also found no evidence that this trend varied by age or sex (fig 1, table 1). These findings update a previous study that found no increase in IBD in the Oxford region from 1971 to $1985 .{ }^{6}$ Whatever caused the marked increases in CD and UC in the mid-20th century, these factors must have stabilised in the Oxford region. We also found no increase in $\mathrm{CD}$ or UC in those cohorts eligible for measles vaccine as infants (table 2).

Our study is not one of true incidence. Firstly, it includes only hospitalised patients. However, most young patients with CD or UC are likely to be admitted to hospital at least once. Secondly, we took five year period prevalence as a proxy for incidence. This was because the date of first-ever diagnosis of CD or UC was not recorded in routine hospital statistics. The older the patients, the more likely it is that our proxy for incidence will include some prevalent cases. This should not materially affect our comparisons of young people between different time periods. Even with these limitations, our data are the best available from routine morbidity statistics in England over such a long time span.

Our findings on trends contrast with studies from Scotland where a threefold rise in juvenile onset CD (less than 17 years of age) was reported from 1968 to $1983 .{ }^{9}$ This upward trend was subsequently reported to continue up to $1995 .^{10}$ The initial increase in CD in Scotland was partially offset by a marginal decline in $\mathrm{UC}^{9}$ but, more recently, the incidence of UC in the young was also reported to have increased. ${ }^{10}$ However, the incidence of CD among adults in Scotland also has continued to increase, ${ }^{11}$ in contrast with stable rates in other westernised countries. ${ }^{1}$ Thus, the reported increase in CD in the young in Scotland may simply be a reflection of a general increase in CD there, and not be specific to the young. Trends and periods of stabilisation have varied between 
Table 2 Age specific rates* for hospitalised incidence of Crohn's disease and ulcerative colitis for the five year birth cohorts, 1962-1966-that is, born before the introduction of the measles vaccination programme-and 1967-1971-that is, born in the five years afterwards; and the rate ratios with $95 \%$ confidence intervals

\begin{tabular}{|c|c|c|c|c|c|c|}
\hline \multirow[b]{2}{*}{ Age $(y)$} & \multicolumn{2}{|c|}{$1962-1966$} & \multicolumn{2}{|c|}{$1967-71$} & \multirow[b]{2}{*}{ Rate ratio } & \multirow{2}{*}{$\begin{array}{l}95 \% \text { Confidence } \\
\text { interval }\end{array}$} \\
\hline & $\mathrm{N}$ & Rate & $\mathrm{N}$ & Rate & & \\
\hline \multicolumn{7}{|l|}{ Crohn's disease } \\
\hline $25-29$ & 80 & 11.4 & 70 & 10.1 & 0.88 & 0.64 to 1.23 \\
\hline $20-24$ & 70 & 10.2 & 67 & 10.4 & 1.02 & 0.72 to 1.43 \\
\hline 15-19 & 43 & 6.2 & 43 & 6.3 & 1.02 & 0.66 to 1.56 \\
\hline $15-29$ & 193 & 9.3 & 180 & 8.9 & $0.96 \dagger$ & 0.78 to 1.18 \\
\hline \multicolumn{7}{|l|}{ Ulcerative colitis } \\
\hline $25-29$ & 53 & 7.5 & 51 & 7.3 & 0.97 & 0.66 to 1.44 \\
\hline $20-24$ & 40 & 5.9 & 37 & 5.8 & 0.98 & 0.62 to 1.55 \\
\hline $15-19$ & 18 & 2.6 & 24 & 3.5 & 1.35 & 0.73 to 1.53 \\
\hline $15-29$ & 111 & 5.4 & 112 & 5.5 & $1.04 \dagger$ & 0.79 to 1.36 \\
\hline
\end{tabular}

*The three 5-year age groups 15-19,20-24, and 25-29 years are the only age groups within our dataset that are covered by five years of births before and after the introduction of the measles vaccination programme. †Age adjusted ratio.

Table 3 Summary of results from previous studies reporting on the association between measles vaccine and Crohn's disease and ulcerative colitis; and comparison with the ORLS study reported in this paper

\begin{tabular}{|c|c|c|c|c|}
\hline \multirow[b]{2}{*}{ Study } & \multicolumn{2}{|c|}{ Crohn's disease } & \multicolumn{2}{|c|}{ Ulcerative colitis } \\
\hline & Relative risk* & $\begin{array}{l}95 \% \text { Confidence } \\
\text { interval }\end{array}$ & Relative risk* & $\begin{array}{l}95 \% \text { Confidence } \\
\text { interval }\end{array}$ \\
\hline $\begin{array}{l}\text { Hypothesis generating } \\
\text { Thompson et al (1995) } \\
\text { Hypothesis testing }\end{array}$ & 3.01 & 1.5 to 6.3 & 2.53 & 1.2 to 5.6 \\
\hline Feeney et al (1997) & $1.08^{*}$ & 0.6 to 1.9 & $0.97^{*}$ & 0.6 to 1.6 \\
\hline Morris et al $(2000)^{4}$ & 0.67 & 0.3 to 1.6 & 0.57 & 0.2 to 1.6 \\
\hline Davies et al $(2001)^{5}$ & $1.11^{*}$ & 0.3 to 4.7 & $1.05^{*}$ & 0.2 to 5.4 \\
\hline The three studies & 0.95 & 0.6 to 1.5 & 0.92 & 0.6 to 1.4 \\
\hline ORLS study ( $45 \%$ vaccinated) & 0.91 & 0.5 to 1.4 & 1.09 & 0.5 to 1.8 \\
\hline
\end{tabular}

countries and populations. ${ }^{1}$ We suggest that the study of such variation could provide clues about the aetiology of IBD.

\section{Association between measles vaccine and IBD}

Our finding of a lack of association between the introduction of the measles vaccination programme and CD or UC is based on an ecological analysis. Findings from such analyses generally need to be interpreted with caution because of the potential for confounding. Might a true association between measles vaccine and IBD have been obscured by confounding in our study? If so, some factor(s) would have had to be highly associated with CD and UC, but to have acted in an equal but opposite way over the precise period that measles vaccination was introduced. This seems unlikely.

The original study ${ }^{2}$ that reported the positive association between measles vaccine and IBD had methodological weaknesses. $^{12}$ In particular, case ascertainment differed between the vaccinated and unvaccinated cohorts, a limitation that could explain part, and perhaps all, of the higher rates found in the vaccinated individuals. A subsequent cohort study ${ }^{4}$ and two subsequent case-control studies ${ }^{35}$ found no increased risk (table 3 ). Our own results from the Oxford linkage data, together with those from the three other hypothesis testing studies, are inconsistent with the RRs of 3.0 and 2.5 found in the original study. The lack of any significant association between measles vaccine and CD or
UC found by our ecological study and the other hypothesis testing studies, together with a plausible explanation (caseascertainment bias) to account for the original finding of higher rates in the vaccinated cohort, provide strong evidence against measles vaccine being associated with an increased risk of CD or UC in later life.

In summary, we found little change in the overall incidence of $\mathrm{CD}$ or UC in the Oxford region over the 20 years 1979 to 1998, no increase in young people, or in cohorts covered by the measles vaccination programme. Studying variations in the incidence of $\mathrm{CD}$ and UC between calendar periods and between countries may offer clues to aetiological factors. Our findings show that the introduction of measles vaccination is unlikely to be one of these factors.

\section{Contributors}

MG proposed the study. VS analysed the data. Both authors designed the study and wrote the manuscript. Both are guarantors.

\section{Authors' affiliations}

V Seagroatt, M J Goldacre, Unit of Health-Care Epidemiology, Department of Public Health, University of Oxford, UK

Funding: the Unit of Health-Care Epidemiology and its work on the Oxford Record Linkage Study are funded by the Research and Development Directorate of the Department of Health and Social Care (South). 
Conflicts of interest: none declared.

\section{REFERENCES}

1 Logan RF. Inflammatory bowel disease incidence: up, down or unchanged? Gut 1998;42:309-11.

2 Thompson NP, Montgomery SM, Pounder RE, et al. Is measles vaccination a risk factor for inflammatory bowel disease? Lancet 1995;345:1071-4.

3 Feeney M, Clegg A, Winwood P, et al. A case-control study of measles vaccination and inflammatory bowel disease. The East Dorset Gastroenterology Group. Lancet 1997;350:764-6.

4 Morris DC, Montgomery SM, Thompson NP, et al. Measles vaccination and inflammatory bowel disease. Am J Gasteroenterol 2000;95:3507-12.

5 Davis RL, Kramarz P, Bohlke K, et al. Measles-mumps-rubella and other measles-containing vaccines do not increase the risk for inflammatory bowel disease: a case-control study from the Vaccine Safety Datalink project. Arch Pediatr Adolesc Med 2001;155:354-9.
6 Primatesta P, Goldacre MJ. Crohn's disease and ulcerative colitis in England and the Oxford record linkage study area: a profile of hospitalised morbidity. Int J Epidemiol 1995;24:922-8.

7 Numerical Algorithms Group. GLIM4. The statistical system for generalized linear interactive modelling. Oxford: Numerical Algorithms Group, 1993.

8 Public Health Laboratory Service. http://www.phls.co.uk/topics_az/ vaccination/cover.htm (accessed 19 Dec 2002).

9 Barton JR, Gillon S, Ferguson A. Incidence of inflammatory bowel disease in Scottish children between 1968 and 1983; marginal fall in ulcerative colitis, three-fold rise in Crohn's disease. Gut 1989;30:618-22.

10 Armitage E, Drummond HE, Wilson DC, et al. Increasing incidence of both juvenile-onset Crohn's disease and ulcerative colitis in Scotland. Eur J Gastroenterol Hepatol 2001;13:1439-47.

11 Kyle J. Crohn's disease in the northeastern and northern Isles of Scotland: an epidemiological review. Gastroenterology 1992; 103:392-9.

12 Farrington P, Miller E. Measles vaccination as a risk factor for inflammatory bowel disease. [Letter]. Lancet 1995;345:1362.

\section{APHORISM OF THE MONTH} William Morris on health

"At least I know this, that if a person is overworked in any degree they cannot enjoy the sort of health I am speaking of; nor if they are continually chained to one dull round of mechanical work with no hope at the other end of it; nor if they live in continual sordid anxiety for their livelihood; nor if they are ill-housed; nor if they are deprived of all enjoyment of the natural beauty of the world; nor if they have no amusement to quicken the flow of their spirits from time to time; all these things, which touch more or less directly on their bodily condition, are born of the claim I make to live in good health." William Morris, 1884 (with acknowledgement to Alex Scott-Samuel). 